\title{
Research on wind field calculation method category Qiuyun $\mathrm{Mo}^{1,2}$, Junjian $\mathrm{Shi}^{2}$, Shunkang Yan ${ }^{2}$, Fei Deng ${ }^{2}$, XiChang $\mathrm{Liu}^{2}$ \& Yongqing Yin $^{2}$ \\ ${ }^{1}$ Guangxi Experiment Center of Information Science, Guilin University of Electronic Technology, Guilin, 541004, China \\ ${ }^{2}$ Department of Electrical and Mechanical Engineering, Guilin University of Electronic Technology, Guilin, 541004, China
}

Keywords: wind field, simulate and forecast, classify, advantage and disadvantage.

\begin{abstract}
As the most important factor for the efficiency of wind power equipment, the wind also is an important guarantee during their work. For the key technology of the research on wind power equipment, how to simulate the wind precisely have been concerned more and more widely. This paper analyzes lots research about both wind equipment and wind field, classifies all wind field calculation method by the perspectives of mathematical model and simulation principle. At last, sum up both advantage and disadvantage of all categories.
\end{abstract}

\section{Introduction}

As deeper study of wind power equipment, the importance of research on wind field also reflected more. But the wind affected by temperature, pressure and the influence of many other factors such as terrain, and with strong stochastic volatility. According to different engineering background and constraints, many scholars put forward the different method to establish the wind speed prediction models, in fact also for wind field. Only confirm the calculation method first, then adopt correct wind field model, after them can you get the wind you want. This article classifies and elaborates wind calculation method by the point of basic principle and established wind field model: based on the probability statistic, empirical formula and combination of wind speed forecasting method.

\section{Based on the Probability Characteristic (BPC)}

Since wind considered as stationary Gauss random process, combined with the mathematical description of the language of stochastic process, some scholars attempted to simulate wind by probability statistics and related knowledge, then established the direct way to forecast wind: Based on the Probability characteristic (BPC). But as the early related studies not for wind power equipment, wind field is not the main object of study, only as a reference, so that the results only reflect the randomness [1].

This kind of method mainly simulating and fitting the wind speed by distribution model, the main model is Weibull model and improved model Rayeigh distribution[2]. In 1939, Swedish physicist Wallodi Weibull proposed Weibull distribution model, which is the theoretical basis for reliability analysis and life detection. Most data show that the wind speed is also consistent with the Weibull distribution. Weibull distribution of many forms, including 1 parameter, 2 parameters, 3 parameters and mixed Weibull. The 3 parameters mean position, shape and size parameter, and the shape parameter is the most important.

Some scholars analyzed the result of BPC by the way of numerical analysis and found the deviation. Also found that, compared with the measured data, the result of BPC only conforms to statistical but fit the actual wind little. The sampling period is too short which makes results just data but cannot reflect the actual situation.[3] At the same time, some scholars improved the numerical analysis results, such as revise parameter, increase the calculation steps and established new objective function. Some scholars introduced the method of least squares to estimate the parameters of the improved support vector machine method[4].

Predicting and calculating wind field by probability statistics directly can reflect the randomness, 
but data shows inevitable distortion. Weibull distribution is an example, predicting wind by double parameter Weibull distribution function, the theory of numerical error can be $2 \%$. So there are following two kinds of calculation methods.

The example of BPC is shown as follows:

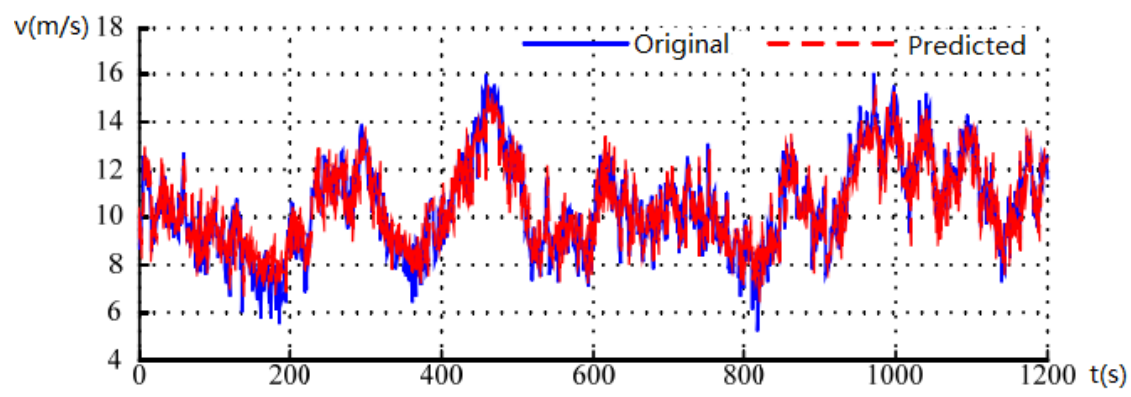

Fig.1 The example of BPC

\section{Based on Empirical Formula (BEF)}

In the actual project, the wind load is defined as the combination of mean wind and fluctuating wind, also some will call mean wind the steady wind. That is:

$$
V=V_{\text {fluctauting }}+V_{\text {mean }}
$$

The study found that the fluctuating wind is a time-varying stochastic process. It also changes in height and surface roughness. At present, through the combination of the empirical formula and a large number of experimental data phase, forming basic method system of fluctuating wind calculation. At the same time, method for forecasting wind speed which is now used in many of the engineering application[5][6].

Steady wind calculation. Steady wind can considered as long cycle process, so in the dynamics analysis often characterized the steady wind load as static. And, the mean wind speed increases with the increase of the height. Through long time observation of average wind speed and integration of data, many scholars think that the average wind speed consistent with the distribution function Weibull:

$$
V_{h}=V_{\text {ref }}\left(\frac{h}{h_{\text {ref }}}\right)^{\frac{1}{n}}
$$

$V_{h}$ means the wind speed at the height of $h, V_{\text {ref }}$ means the reference height wind speed, $1 / n$ is the function of surface roughness and Reynolds.

At the same time, some scholars also simplified the model mentioned above, only to calculate the average wind speed, presents exponential model and logarithmic model rules to describe the average wind with altitude change:

$$
\frac{\overline{\mathrm{v}}(\mathrm{z})}{\overline{\mathrm{v}}\left(\mathrm{z}_{1}\right)}=\left(\frac{\mathrm{z}}{\mathrm{z}_{1}}\right)^{\alpha} \quad \frac{\overline{\mathrm{v}}(\mathrm{z})}{\overline{\mathrm{v}}\left(\mathrm{z}_{1}\right)}=\frac{\ln \left(\mathrm{z} / \mathrm{z}_{0}\right)}{\ln \left(\mathrm{z}_{1} / \mathrm{z}_{0}\right)}
$$

$\bar{v}(z)$ means the average wind speed in the height of $z, z_{1}$ and $\bar{v}\left(z_{1}\right)$ are reference height and its speed. $\alpha$ is surface roughness.

The calculation of fluctuating wind. We can calculate fluctuating wind by power spectrums which were established by predecessors. The fluctuating wind divided into horizontal and vertical. And the cercal often for structure design, Davenport, Kamal, Harris and other spectrums mainly used for this situation. The vertical wind spectrum are Panofsky-McComic, Lumley-Panofsky and so on.

Due to the difference of climate characteristics in each area, and the wind affected by pressure and temperature, fluctuating wind prediction method which extracted based on experience in function cannot fit all engineering backgrounds. During the calculation should also be combined 
with the measured data, select the appropriate wind spectra and revise function after compared test. After those works can you predicting the wind field[7].

The example of BEF is shown as follows:

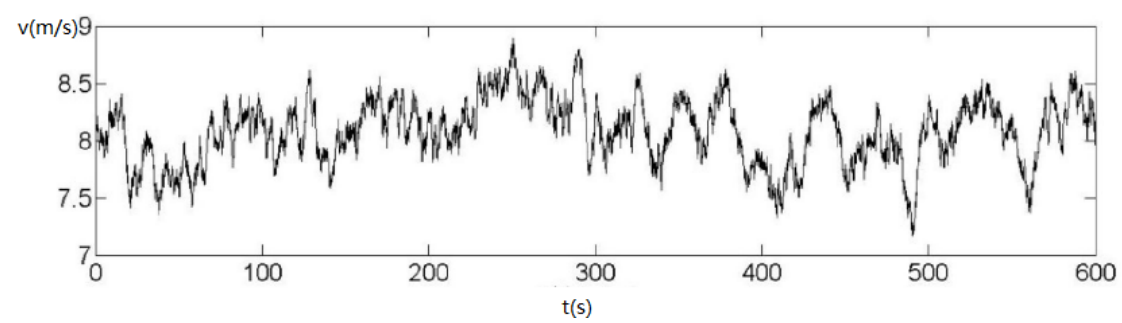

Fig.2 The example of BEF

\section{Combination of Wind speed Forecasting (CWF)}

Based on the simulation of fluctuating wind to predict wind field is proposed in the solution of building process, at the same time for the stable reliability problem of mechanical structure of wind power generation system part, can also use this kind of method to simulate the wind field. But for wind farms or small fan, for the study of the power part is more and more thorough, the request for wind field simulation also more[8]. So some scholars attempt define combination model of wind speed thich contains: the basic wind, gust, gradient wind and random wind:

$$
\mathrm{V}=v_{\text {basic }}+v_{\text {gust }}+v_{\text {gradient }}+v_{\text {random }}
$$

Among them, the basic wind regard as the average wind, and it can through numerical computation, or using the Weibull distribution which proposed in BEF. And the other three part of the wind speed are obtained by its respective mathematical model and objective function calculation.

Since in CWF the wind more like a signal, therefore CWF mainly applied in the study as maximum power point tracking control and transmission loss. So the final result mostly appeared as a signal form, as an input to the system related research. Compare to BEF, both of them are based on probability statistics. But for different requirement, the mathematical model is different and makes the result different[9][10].

The example of BEF is shown as follows:

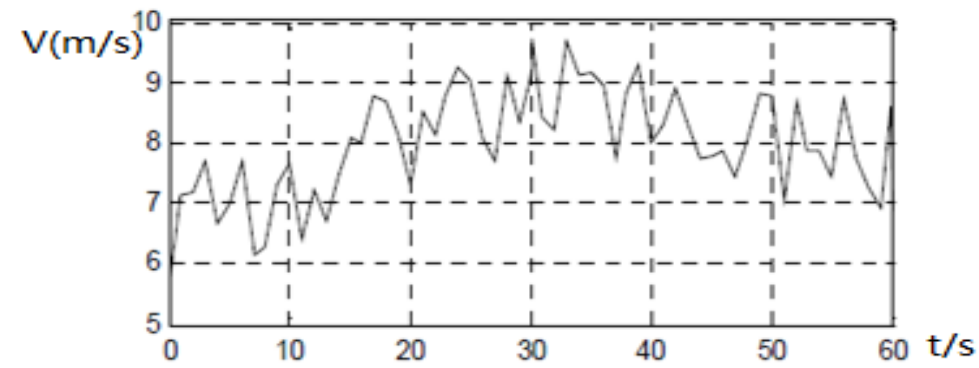

Fig.3 The example of CWF

\section{Summary}

By the perspectives of mathematical model and simulation principle, This paper analyzes classifies all wind field calculation method into three kinds: Probability statistic, empirical formula and combination of wind speed forecasting method. Elaborate and compare the detail about each method, as follows: 


\begin{tabular}{|l|l|l|l|}
\hline $\begin{array}{l}\text { Method } \\
\text { Category }\end{array}$ & $\begin{array}{l}\text { Mathematic } \\
\text { al Model }\end{array}$ & $\begin{array}{l}\text { Advantage and } \\
\text { disadvantage }\end{array}$ & $\begin{array}{l}\text { Application } \\
\text { Area }\end{array}$ \\
\hline $\begin{array}{l}\text { Probability } \\
\text { Characteristic }\end{array}$ & $\mathrm{v}=v_{s}$ & $\begin{array}{l}\text { Has good } \\
\text { randomness; cannot } \\
\text { fit virtual data well. }\end{array}$ & $\begin{array}{l}\text { Undemandi } \\
\text { ng wind } \\
\text { field. }\end{array}$ \\
\hline $\begin{array}{l}\text { Empirical } \\
\text { Formula }\end{array}$ & $\begin{array}{l}V \\
=V_{\text {fluctauting }} \\
+V_{\text {mean }}\end{array}$ & $\begin{array}{l}\text { Not only } \\
\text { randomness, but also } \\
\text { volatility; lacks } \\
\text { detail about wind } \\
\text { and still will have } \\
\text { major error. in }\end{array}$ & $\begin{array}{l}\text { Applied } \\
\text { structure } \\
\text { and } \\
\text { reliability } \\
\text { analyzsis; } \\
\text { optimizatio } \\
\text { n design. }\end{array}$ \\
\hline $\begin{array}{l}\text { Combination } \\
\text { of Wind speed }\end{array}$ & $\begin{array}{l}\mathrm{V} \\
=v_{\text {basic }} \\
+v_{\text {gust }} \\
+v_{\text {gradient }} \\
+v_{\text {random }}\end{array}$ & $\begin{array}{l}\text { Has volatility and } \\
\text { more detail about } \\
\text { wind; lack of } \\
\text { randomnes more } \\
\text { likes kind of output } \\
\text { signal. }\end{array}$ & $\begin{array}{l}\text { For } \\
\text { electricity } \\
\text { system, } \\
\text { power } \\
\text { control and }\end{array}$ \\
\hline
\end{tabular}

\section{Acknowledgements}

The research work was supported by Natural Science Foundation of China under Grant No. 51465010 and Guangxi Key Laboratory of Manufacturing System \& Advanced Manufacturing Technology under Grant No. 14-045-15-010Z.

\section{References}

[1] Tony Burton, Wind Power Technology. Beijing: Science Press, 2007.

[2] Wang Liang, Hone-Wei Tan, Natural Ventilation Under Wind Speed Condition Based On Weibull Statistic Characteristics. Acta Energiae Solaris, 2, pp.345-350,2014.

[3] Ding Ming, Wu Wei, Research on Forecasting of Probabilistic Distribution Parameters of Wind Speed and Its Application, Power System Technology.32(14),pp,9-14,2008.

[4] Xiao-Lan Wang, Ming-Wei Wang, Short-Term Wind Speed Forecasting Based on Wavelet Decomposition and Least Square Support Vector Machine. Power System Technology, 34(1), pp.179-184,2010.

[5] Kariniotakis G, Stavrakakis G N, Wind power forecasting using advanced neural network models. IEEE Trans on Energy Conversion,11(14).pp.762-767,1996.

[6] Torres J L, Garcia A. \& Blas M De, Forecast of hourly average wind speed with ARMA models in Navarre. Solar Energy, 79, PP.67-76,2005.

[7] Xi-Qian Zhang, Yong Ge, Advances in research of simulation technology of fluctuation wind loading. Journal of Earthquake Engineering And Engineering Vibration, 28(6), pp,207-209,2008.

[8] Zhang Wen-Fu, Ma Cheng-heng, Some issues on AR models for wind field simulation. Chinese Journal of Computational Mechanics.26(1),pp,125-129,2009.

[9] Xue-Ke Zheng, Mo Qiu-Yun, Wind Field Simulation In The Wind Power Generation System Based On LabVIEW. Journal of Guilin University of Electronic Technology, 33(1), pp,46-48,2013.

[10]Du Zuo-Yi, Ma L.Y, Wind Speed Simulation Based on Matlab/Simulink. Science and Technology of West China,12(12),pp,46-47,2013. 